\title{
Immigrant From High Tuberculosis Prevalent Area
}

National Cancer Institute

\section{Source}

National Cancer Institute. Immigrant From High Tuberculosis Prevalent Area. NCI

Thesaurus. Code C102648.

An individual that has migrated from a country with a high occurrence of tuberculosis. 